\title{
УРОВНИ МИКРОРНК (МКРНК) ПРИ ЗАБОРЕ КРОВИ ИЗ НИЖНИХ КАМЕНИСТЫХ СИНУСОВ У ПАЦИЕНТОВ С БОЛЕЗНЬЮ ИЦЕНКО-КУШИНГА (БИК) И АКТГ-ЭКТОПИРОВАННЫМ СИНДРОМОМ
}

\author{
Малыгина А.А., Белая Ж.Е., Никитин А.Г., Кошкин Ф.А., Ситкин И.И., Трухина Д.А., Хандаева П.М., \\ Мельниченко Г.А.
}

ФГБУ «НМИЦ эндокринологии» Минздрава России, Москва

ЦЕЛЬ: выявить различия в уровнях мкРНК в образцах крови, оттекающих от гипофиза у пациентов с БИК и АКТГ-эктопированным методом NGS.

МАТЕРИАЛЫ И МЕТОДЫ: вЫПолнено одноцентровое одномоментное исследование случай-контроль. В исследование включены 24 пациента с БИК (3 мужчин, 21 женщина; возрастная медиана 47 лет) и 12 пациентов с АКТГ-эктопированным синдромом (4 мужчин, 8 женщин; возрастная медиана 54 года). Всем пациентам выполнен селективный забор крови из нижних каменистых синусов (НКС) для уточнения источника гиперпродукции АКТГ. Забор крови из НКС осуществлялся до введения стимуляционного агента, в пробирки с ЭДТА, далее образцы крови были дважды центрифугированы на скорости 3000 оборотов в минуту в течение 15 минут при температуре $+5^{\circ} \mathrm{C}$ и заморожены при температуре $-80^{\circ} \mathrm{C}$. Выделение микроРНК из плазмы крови проводили с помощью miRNeasy Serum/Plasma Kit («Qiagen», Германия) согласно инструкции компании-производителя на автоматической станции QIAcube («Qiagen», Германия). Для предотвращения деградации в выделенную РНК добавляли 1 ед. RiboLock RNase Inhibitor («Thermo Fisher Scientific», США) на 1 мкл раствора нуклеиновых кислот. Концентрацию суммарной РНК в водном растворе оценивали на спектрофотометре NanoVue Plus («GE Healthcare», Великобритания). Для дальнейшей работы отбирали образцы с концентрацией суммарной РНК в водном растворе не ниже 5 нг/мкл. Экспрессию микроРНК анализировали с помощью секвенирования на Illumina NextSeq 500 (Illumina NextSeq 500, США). Библиотеки были подготовлены с помощью QIAseq Stranded RNA Library Kit в соответствии со стандартными протоколами производителя. Анализ и интерпретация данных были проведены при помощи Qiagen GeneGlobe Data Analysis Center.

PЕЗУЛЬТАТЫ: были обнаружены 1167 дифференциально экспрессирующихся мкРНК с уровнем значимости $<0,05$ после поправки на множественность сравнений. По достоверности обнаруженных различий мкРНК они были разделены на три группы — группа 1 с числом прочтений более 10 в обоих группах сравнения, группа 2 с числом прочтений менее 10 в одной из групп, группа 3 с числом прочтений менее 10 в обоих группах. Группа 1 состояла из 108 мкРНК. Для дальнейшей верификации методом ПЦР в реальном времени, планируется использовать следующие наиболее отличающиеся по профилю экспрессии между двумя группами мкPHK: miR-383-3p, miR-4290 и miR-6717-5p, экспрессия которых была повышена в группе пациентов с БИК по сравнению с пациентами из группы АКТГ-ЭС в 48,34 раз ( $p=0,0002)$, в 7,26 раз $(p=0,007)$ и в 5,35 раз ( $p=0,0013)$ соответственно, а также выявленные ранее в ходе анализа 24 образцов (12 пациентов с БИК, 12 пациентов с АКТГ-ЭС) методом NGS miR-1203, miR-1229-3p, miR-639, уровень экспрессии которых был снижен у пациентов с БИК по сравнению с пациентами из группы АКТГ-ЭС в 36,74 раз $(p=0,001)$, в 78,3 раз $(p=0,003)$, в 73,22 раза $(p=0,002)$ соответственно, а также miR-302c-3p, уровень экспрессии которой был повышен в группе пациентов с БИК по сравнению с АКТГ-ЭС в 92,69 раз ( $p=0,001)$.

ВЫВОдЫ: в ходе NGS удалось выявить группу мкPHK, отличающихся по профилям экспрессии между пациентами с БИК и АКТГ-эктопированным синдромом. Планируется верификация выявленных мкРНК в периферической крови, используя метод ПЦР в реальном времени на большей выборке пациентов. 